\title{
$\mathrm{RSH}$ 를 이용한 정상상태 운전 유도전동기의 회전속도 추정
}

\begin{tabular}{|c|}
\hline 논 문 \\
\hline $60-9-23$ \\
\hline
\end{tabular}

\section{Speed Estimation of Induction Motor in Steady State Using the RSH}

\author{
양 철 오*·박 규 남** 송 명 현 ${ }^{+}$
}

(Chul-Oh Yang $\cdot$ Kyu-Nam Park $\cdot$ Myung-Hyun Song)

\begin{abstract}
The slip frequency is included in feature frequency for fault diagnosis of rotor bar, so rotating rotor speed is needed. In this study, rotor slot harmonic(RSH) method is suggested for speed estimation of induction motor. When the rotor is rotating, motor current signal include the harmonic signal of back-emf voltage related with number of rotor slot. So from the power spectrum of current signal, the rotor speed can be founded. This method of rotor speed estimation gives the slip frequency, and the feature frequency of rotor bar fault can be calculated. Comparing with stroboscope speed meter, the error rate of suggested method is less than $0.1[\%]$.
\end{abstract}

Key Words : RSH(Rotor Slot Harmonics), Sensorless estimation, Induction motor, Rotating speed

\section{1. 서 론}

유도전동기는 전원공급이 용이하고 속도제어를 위한 장치 구성비용이 저렴하다는 구조적인 강점 때문에 많은 주요 기 기의 구동장치로 산업영역 전반에 걸쳐 폭넓게 사용되고 있 다. 유도전동기의 갑작스런 고장은 구동장치를 사용하는 전 체 시스템에 대한 신뢰도 및 안전성을 저하시키고 경제적인 손실을 초래할 뿐만 아니라 인명 피해의 위험 등 많은 문제 를 발생할 수 있다. 따라서 중요한 전동기는 어떤 형태로든 초기 결함을 감지하여 계획적인 예방정비 또는 적기에 수리 가 이루어질 수 있는 결함검출 방법이 필요하다[1].

전동기의 결함 상태는 전동기의 회전속도와 밀접한 상관 관계를 가지므로 전동기의 상태 진단에 있어 회전속도의 측 정은 매우 중요한 부분이다. 특히 전류의 스펙트럼 분석에 의한 회전자 바 고장 진단에서는 유도전동기의 회전 속도 측정이 필수적으로 선행되어야 한다. 따라서 정확한 전동기 회전속도 측정을 위해서 레졸버나 펄스 엔코더와 같은 기계 적인 속도 센서를 이용하여 속도 정보를 얻어내는 방법이 사용되었으나, 이러한 기계적인 센서는 주변 환경이나 전동 기의 설치조건에 따라서 속도 측정이 어려운 경우가 많을 뿐만 아니라 고가의 비용을 부담해야 하는 단점이 있어, 속 도 센서리스 회전속도 추정에 대한 연구가 수행되었다.

초기 센서리스 속도 추정 연구는 전동기의 전압과 전류를 측정하여 전동기 모델로부터 속도를 연산하는 방식을 대부 분 채택하였고[2], 이 후 센서 없는 전동기 회전속도 예측에

\footnotetext{
* 정 회 원 : 순천대학교 공대 전기공학과 박사과정

** 정 회 원 : 순천대학교 공대 전기제어공학과 교수

† 교신저자, 정회원 : 순천대학교 공대 전기제어공학과 교수

E-mail : mhsong@sunchon.ac.kr

접수일자 : 2011년 6월 2일

최종완료 : 2011년 7월 18일
}

대한 연구에는 확장된 칼만 필터를 이용한 유도전동기의 속 도추정 방법[3], $\mathrm{FNN}$ 과 $\mathrm{ANN}$ 을 이용한 추정방법[4], 이원관 측기를 이용한 유도전동기의 속도 추정 방법[5], 이 외에도 속도 센서 없이 전동기의 회전속도를 추정하는 방법에 대한 여러 가지 연구가 활발히 진행되어 왔다[6-7]. 하지만 이러 한 방법들은 시뮬레이션 조건에서는 정확한 속도 추정 성능 을 가지지만, 부하의 상태나 온도에 따라 가변되는 고정자 및 회전자 저항으로 인해 실제 유도전동기의 속도를 정확하 게 추정하기 어려운 단점이 있다.

일반적으로 전동기의 상태 진단을 위한 센서리스 유도전 동기의 회전속도 추정에는 주로 순시 신호의 주파수 스펙트 럼을 이용한 회전수 예측 방법을 사용한다[8]. 주파수 스펙 트럼을 이용한 회전수 예측 방법은 유도전동기의 회전에 의 해 발생하는 주파수 신호를 분석하여 속도를 추정하는 방법 이므로, 속도 변화가 큰 전동기의 기동 중 과도상태에서는 회전속도 추정이 어려운 단점이 있지만, 속도 변화가 크지 않은 정상상태 운전 중에는 정확한 속도 추정이 가능하다. 전동기의 상태 진단은 전동기의 정상상태 운전 중에 이루어 지므로 전동기의 제어 목적이 아닌 상태 진단을 목적으로 하는 센서리스 회전속도 추정에는 주파수 스펙트럼을 이용 한 회전수 추정 방법이 유리하다.

유도전동기는 회전자의 회전에 따라 전류 신호에 회전자 의 슬롯 하모닉(RSH)이 발생한다. 따라서 이 회전자 슬롯 하모닉 스펙트럼을 이용하여 회전자의 회전 속도를 측정할 수 있다. 이러한 회전속도 측정 방법은 종래의 센서리스 회 전 속도 추정 방법보다 더욱 정확한 회전 속도를 얻어낼 수 있는 있으므로, MCSA(Motor Current Signature Analysis) 를 통한 온라인 회전자 바 고장 진단을 위해 필요한 회전 속도 정보를 얻기에 적절하다. 주파수 스펙트럼을 이용한 유도전동기의 회전 속도 측정 방법은 대부분 전류 신호의 회전자 슬롯 하모닉 스펙트럼을 이용하여 유도전동기의 속 도를 추정한다[9-14]. 이 연구들에서는 유도전동기 전류 신 
호의 주파수 스펙트럼에서 회전속도에 대응하는 주파수 대 역에서 슬롯 하모닉 성분이 발생하므로 회전속도 추정이 가 능함을 제시하긴 하였으나 실시간 회전속도 추정 가능 여부 에 대해서는 고려하지 않았다.

유도전동기의 온라인 실시간 상태 진단을 위해서는 실시 간 회전속도 추정이 필요하다. 그리고 유도전동기의 전류 신호에는 회전자의 회전에 의해 발생하는 $\mathrm{RSH}$ 성분이 포함 되어 있으므로 이를 이용해 회전속도 추정이 가능하다. 따 라서 본 논문에서는 유도전동기의 정상상태 운전 중에 실시 간으로 속도센서 없이 유도전동기의 회전속도 추정을 위해 전동기 회전자의 회전에 의해 발생하는 $\mathrm{RSH}$ 성분의 주파수 대역을 실시간으로 찾아내는 방법을 제시함으로써 실시간 회전속도 추정이 가능하게 하는데 그 목적이 있다.

\section{2. 본 론}

\subsection{RSH를 이용한 유도전동기 회전속도 추정}

유도전동기의 회전자가 회전할 때 슬롯은 공극에서 하모 닉 성분을 만들어내고, 이로 인해 고정자 권선에 하모닉 전 압이 유도되므로 상 전류 하모닉 성분이 생성된다. 따라서 이를 이용해 고정자 상 전류에서 회전속도에 따른 슬립 하 모닉 성분을 찾는 것이 가능하다. 공극에서 회전자 슬롯의 하모닉은 회전속도에 비례하는 주파수를 발생시킨다. 따라 서 유도전동기의 회전속도는 상 전류의 슬롯 하모닉 주파수 를 이용하여 추정할 수 있다[10].

\subsection{1 회전자 슬롯 하모닉(RSH)}

속도와 관련된 전류 하모닉은 공극 기자력 $(\mathrm{mmf})$ 과 상호 작용하는 공극 투자도 $\left(P_{a g}\right)$ 의 변화에 의해 발생하고, 공극 자속 밀도 $\left(B_{a g}\right)$ 는 식 (1)과 같다.

$$
B_{a g}\left(\varphi_{s}, \theta\right)=M M F_{a g}\left(\varphi_{s}, \theta\right) \cdot P_{a g}\left(\varphi_{s}, \theta\right)
$$

여기서, $\varphi_{s}$ 는 고정자 각 위치, $\theta$ 은 기계적 회전자 위치, $M M F_{a g}$ 는 고정자 전류에 의한 공극 기자력, $P_{a g}$ 는 공극 투 자도.

공극 투자도의 변화는 회전자 슬롯과 회전자의 편심에 의 해 발생한다. 회전자 슬롯에 의해 발생하는 전류 신호의 슬 롯 하모닉 $\left(f_{s h}\right)$ 은 식 (2)에 의해 얻어진다[15].

$$
f_{s h}=f_{e}\left(\left(k R+n_{d}\right)\left(\frac{1-s}{p / 2}\right)+n_{w}\right)
$$

여기서, $f_{e}$ 는 전원주파수, $k=0,1,2 \ldots, R$ 은 회전자 슬롯의 수, $n_{d}=0, \pm 1, \ldots$,는 회전자 편심의 순서, $s$ 는 슬립, $p$ 는 극 수, $n_{w}= \pm 1, \pm 3, \ldots$, 는 공극 기자력 하모닉의 순서.

회전자의 편심이 없는 유도전동기의 회전자 슬롯 하모닉 $(\mathrm{RSH})$ 은 첫 번째 $\operatorname{RSH}\left(k=1, n_{d}=0, n_{w} \pm 1\right.$ 일 때 $)$ 에서 가장
분명하게 나타난다. 따라서 가장 분명하게 나타나는, $n_{w}= \pm 1$ 일 때 하모닉 주파수 $\left(f_{s h \pm 1}\right)$ 는 식 (3)과 같다. 여기 서, $n_{w}=1, n_{w}=-1$ 일 때의 회전자 슬롯 고조파 주파수 대 역을 각각 $f_{s h 1}, f_{s h-1}$ 이라고 하고 두 주파수 대역 $\left(f_{s h 1}\right.$, $\left.f_{s h-1}\right)$ 을 비교하면 식 (4)와 같은 조건을 만족한다. 따라서, $f_{s h 1}$ 은 $f_{s h-1}$ 보다 $2 f_{e}$ 더 높은 주파수 대역에서 발생한다.

$$
\begin{aligned}
& f_{s h \pm 1}=\left(R\left(\frac{1-s}{p / 2}\right) \pm 1\right) f_{e} \\
& f_{s h 1}=f_{s h-1}+2 f_{e}
\end{aligned}
$$

\section{1 .2 유도전동기의 회전속도}

높은 주파수 대역에서는 낮은 파수 대역에서보다 주변 주 파수 성분의 간섭이 적다. 따라서 $f_{s h 1}$ 성분이 주변의 주파 수 성분에 비해 더 분명하게 나타나므로 $f_{s h 1}$ 을 이용하여 유 도전동기의 회전속도를 추정하는 것이 유리하다[16]. $n_{w}=1$ 일 때 회전자 슬롯 하모닉 주파수 $\left(f_{s h 1}\right)$ 는 식 (5)와 같으며, 정리하면 전동기 회전속도 $(N)$ 는 식 (9)와 같다.

$$
\begin{aligned}
& f_{s h 1}=\left(R\left(\frac{1-\frac{N_{s}-N}{N_{s}}}{p / 2}\right)+1\right) f_{e} \\
& R\left(\frac{\frac{N}{N_{s}}}{p / 2}\right)=\frac{f_{s h 1}}{f_{e}}-1 \\
& R\left(\frac{\frac{N p}{120 f_{e}}}{p / 2}\right)=\frac{f_{s h 1}}{f_{e}}-1 \\
& N\left(\frac{R}{60 f_{e}}\right)=\frac{f_{s h 1}}{f_{e}}-1 \\
& N=60\left(f_{s h 1}-f_{e}\right) / R
\end{aligned}
$$

\subsection{3 정상상태 운전 유도전동기의 $\mathrm{RSH}$ 발생 구간}

회전자 슬롯 고조파 대역에서는 주변의 주파수보다 큰 진 폭이 발생한다. 따라서 이 큰 진폭을 갖는 회전자 슬롯 하 모닉 주파수 성분 검출을 통해 유도전동기의 회전속도 추정 이 가능하다[16]. 본 논문에서는 $f_{s h 1}$ 을 검출하기 위해서 유 도전동기의 정상상태 운전구간에서 $f_{s h 1}$ 이 발생할 수 있는 최대/최소 주파수 범위를 설정하고, 그 주파수 범위에서 가 장 큰 진폭을 갖는 주파수 대역을 $f_{s h 1}$ 으로 검출하였다. 정 상상태 운전구간에서 최고 회전속도는 동기속도 $\left(N_{s}\right)$ 를 초과 하지 않으므로 $f_{s h 1}$ 의 최대값 $\left(f_{s h m a x}\right)$ 은, 식 (5)에서 회전속 도가 동기속도 $\left(N_{s}\right)$ 일 때의 $f_{s h 1}$ 으로 식 (10)과 같이 구할 수 있다. 그리고 정상상태 운전구간에서 최저 회전속도는 정격 속도 $\left(N_{r}\right)$ 이므로 $f_{s h 1}$ 의 최소값 $\left(f_{s h m i n}\right)$ 은, 식 (5)에서 회전속 도가 정격속도 $\left(N_{r}\right)$ 일 때의 $f_{s h 1}$ 이다. 본 논문에서는 정격속 도를 초과해서 운전될 경우를 고려하여 식 (11)과 같이 여 유주파수 $\left(f_{m}\right)$ 를 두어 $f_{s h 1}$ 발생 가능 주파수 범위의 최소값 $\left(f_{\text {shmin }}\right)$ 을 설정하였다. 


$$
\begin{aligned}
f_{\text {shmax }}= & \left(R\left(\frac{1}{p / 2}\right)+1\right) f_{e} \\
f_{\text {shmin }} & =\left(R\left(\frac{1-\frac{N_{s}-N_{r}}{N_{s}}}{p / 2}\right)+1\right) f_{e}-f_{m}
\end{aligned}
$$

여기서, $f_{s h \max }$ 은 최대 $f_{s h 1}, f_{s h \min }$ 은 최소 $f_{s h 1}, N_{s}$ 는 동기 속도, $N_{r}$ 은 정격 속도(최대 부하 속도), $f_{m}$ 은 여유 주파수.

\subsection{4 유도전동기의 회전속도 추정 알고리즘}

본 논문에서는 $\mathrm{RSH}$ 를 이용한 유도전동기의 회전속도 추 정 알고리즘을 제안하였다. 그림 1 은 제안한 유도전동기의 회전속도 추정을 위한 알고리즘이고, 다음은 회전속도 추정 알고리즘의 동작 순서에 따른 설명이다.

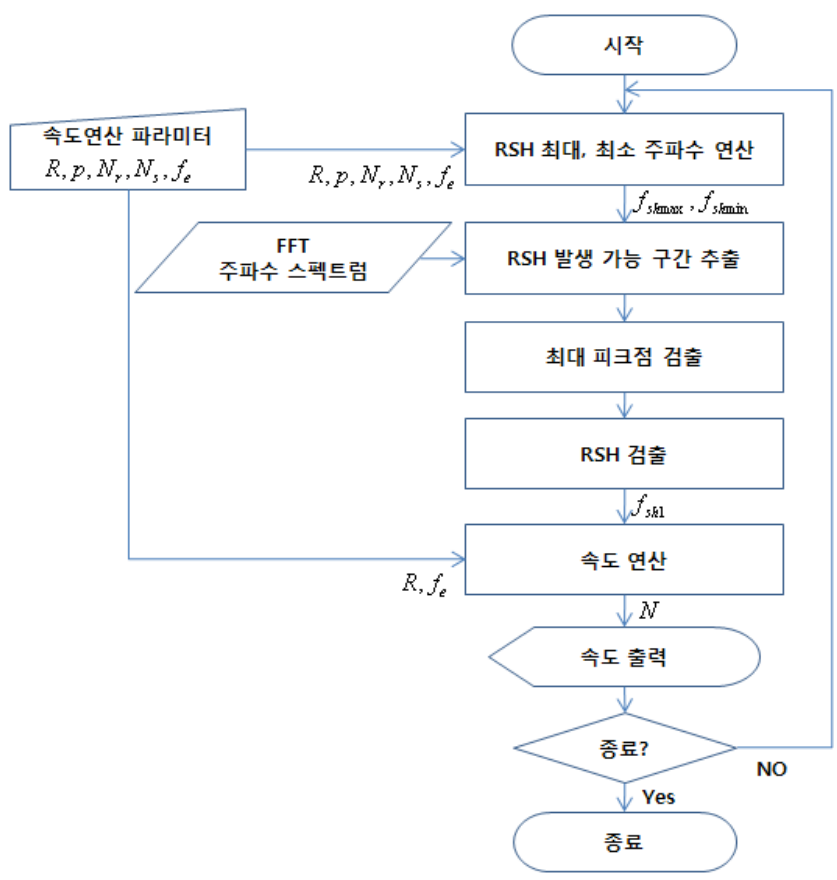

그림 $1 \mathrm{RSH}$ 검출 및 속도 추정 알고리즘

Fig. 1 Algorithm for detection of $\mathrm{RSH}$ and speed estimation

- $\mathrm{RSH}$ 최대, 최소 주파수 연산부에서는 속도 연산 파라미터 $\left(R, p, N_{r}, N_{s}, f_{e}\right)$ 값들을 입력 받아 함수에서 식 (10), (11)의 연산을 통해 각각 $f_{s h m a x}$ 와 $f_{s h m i n}$ 을 출력한다.

- $\mathrm{RSH}$ 발생 가능 구간 추출부에서는 $\mathrm{RSH}$ 최대, 최소 주 파수 연산부에서 출력된 $f_{s h m a x}, f_{s h m i n}$ 값을 입력 받아 FFT 변환된 전류 신호의 주파수 스펙트럼에서 $\mathrm{RSH}$ 발 생 가능 구간을 추출해낸다.

- 최대 피크점 검출부에서는 추출된 주파수 스펙트럼 구간 에서 모든 피크점을 검출하여 최대 진폭값을 찾아내고, 그 진폭값을 $\mathrm{RSH}$ 로 간주하여 $\mathrm{RSH}$ 가 발생한 주파수 대 역 $\left(f_{s h 1}\right)$ 을 출력한다.

- 속도 연산부에서는 출력된 주파수 대역 $\left(f_{s h 1}\right)$ 과 속도 연 산 파라미터의 $f_{e}$ 및 $R$ 을 입력받아 식 (9)의 연산을 통
해 추정된 회전속도 $N$ 을 출력하고 종료 조건이 입력되

기 전까지 속도 추정을 계속한다.

\section{2 실험 결과 및 검토}

\subsection{1 실험장치 구성}

그림 2는 실험에 사용된 시스템의 구성 모습이다. 실험에 는 효성 3 상 유도전동기를 사용하였고, 유도전동기의 부하 실험을 위해 다이나모메타를 결속하였다. 다이나모메타에 연결된 $\mathrm{PC}$ 컨트롤러를 통해 원하는 속도[rpm]로 운전할 수 있어 부하를 조절할 수 있다. 전류 측정을 위해 FLUKE사의 $\mathrm{i} 5 \mathrm{~s}$ AC Current Clamp를 한 상에 연결하였으며, USB-DAQ 보드는 NI(National Instrument)사의 USB 9215A with BNC 사용하였고, USB 2.0 을 통해 노트북 컴퓨터와 연결하였다.

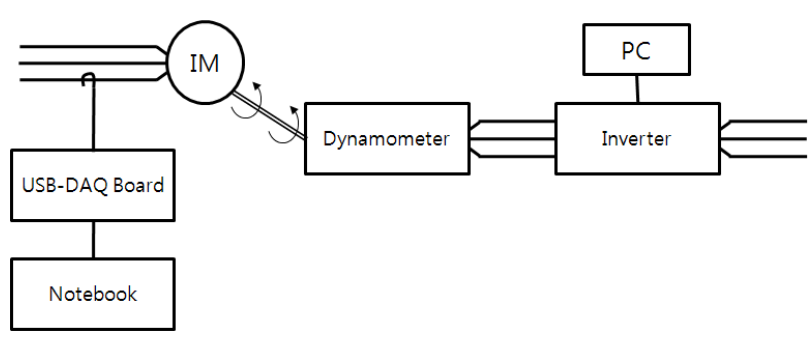

그림 2 실험장치 구성

Fig. 2 Configuration of the experimental system

\subsubsection{RSH 검출 실험}

실험에 사용된 효성 1 마력 유도전동기는 극수 $(p)$ 는 4 극, 회전자 슬롯 수 $(R)$ 는 44 , 동기속도 $\left(N_{s}\right)$ 는 $1800[\mathrm{rpm}]$, 정격 속 도 $\left(N_{r}\right)$ 는 $1690[\mathrm{rpm}]$ 이다. 이 값들을 식 (3)에 대입해 정리하 면 식 (12)를 얻을 수 있다. 따라서 식 (12)를 이용해 실험 전동기의 회전속도 $(N)$ 에 따른 회전자 슬롯 고조파 $\left(f_{s h \pm 1}\right)$ 를 연산 할 수 있다.

$$
f_{s h \pm 1}=\left(22\left(1-\frac{1800-N}{1800}\right) \pm 1\right) 60
$$

그림 3 은 $60[\mathrm{~Hz}]$ 의 전원 전압에서 $1750[\mathrm{rpm}]$ 으로 운전되 는 실험 전동기 전류 신호의 주파수 스펙트럼을 보여준다. 여기서 $n_{w}=1$ 일 때 회전자 슬롯 고조파 주파수 $\left(f_{s h 1}\right)$ 는 $1343[H z]$ 이고 $n_{w}=-1$ 일 때의 회전자 슬롯 고조파 주파수 $\left(f_{s h-1}\right)$ 는 $1223[H z]$ 이다. 두 주파수 대역을 비교하면 $f_{s h 1}$ 은 식 (4)와 같이 $f_{s h-1}$ 보다 $120[H z]$ 높은 주파수 대역에서 발 생한다. 그리고 두 주파수 대역의 진폭의 크기를 비교해보 면 $f_{s h 1}$ 은 $f_{s h-1}$ 보다 높은 주파수 대역에서 발생함에도 불구 하고 진폭의 크기가 더욱 분명하게 나타남을 알 수 있다. $f_{s h 1}$ 은 $f_{s h-1}$ 에 비해 진폭의 크기가 클 뿐만 아니라, 더 높 은 주파수 대역에서 발생하므로 주변 주파수의 간섭이 적어 유도전동기 회전속도 추정에 적용하기가 유리하다. 


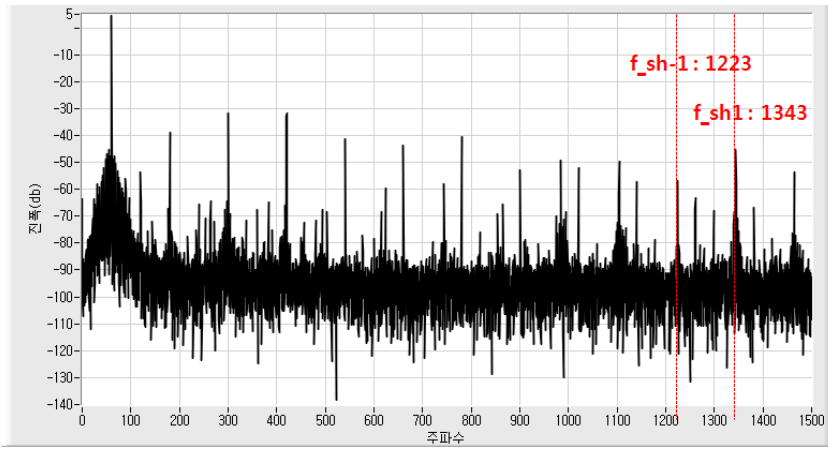

그림 3 회전자 슬롯 하모닉 주파수 $\left(f_{s h \pm 1}\right)$

Fig. 3 Rotor slot harmonic frequency $\left(f_{s h \pm 1}\right)$

\subsubsection{RSH 발생 가능 구간 실험}

그림 4는 회전자 슬롯 하모닉 주파수 발생 가능 구간 내 에서 회전 속도 변화에 따른 회전자 슬롯 하모닉 주파수의 변화를 확인하기 위한 그래프로, 유도전동기를 네 가지 회전 속도 $(1690,1720,1750,1790[\mathrm{rpm}])$ 로 구동시켜 얻은 전류 신 호를 $\mathrm{FFT}$ 변환하여 한 화면에 그린 결과이다. 회전 속도가 증가함에 따라 부하는 작아지므로 회전자 슬롯 하모닉 주파 수의 진폭의 크기는 작아지지만, 각 회전 속도별 그래프에서 회전자 슬롯 주파수 범위에서 가장 큰 진폭을 갖는 주파수 는 회전자 슬롯 하모닉 주파수 $\left(f_{s h 1}\right)$ 임을 확인할 수 있다. 따 라서 회전자 슬롯 주파수 범위에서 진폭이 가장 큰 주파수 성분 $\left(f_{s h 1}\right)$ 을 찾아 식 (9)에 의해 유도전동기의 회전속도를 추정할 수 있다.

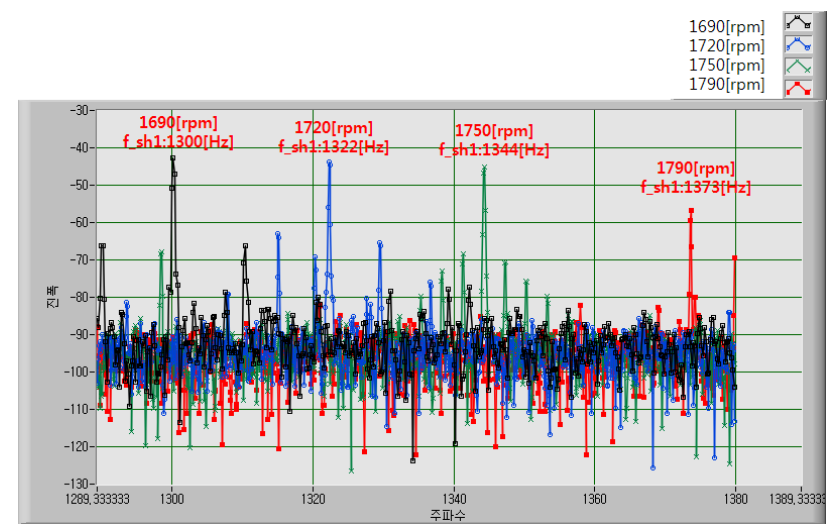

그림 4 회전속도에 따른 슬롯 하모닉 주파수 $\left(f_{s h 1}\right)$ 변화

Fig. 4 Variation of slot harmonic frequency $\left(f_{s h 1}\right)$ according to rotation speed

\subsection{4 유도전동기의 회전속도 추정 실험}

그림 5 는 다이나모메타에 의해 제어되는 유도전동기 운전 속도와 $\mathrm{RSH}$ 속도 추정 알고리즘에 의해 추정된 회전속도를 비교한 그래프이다. 유도전동기의 운전속도를 정격 속도인 $1690[\mathrm{rpm}]$ 에서부터 $1790[\mathrm{rpm}]$ 까지 $10[\mathrm{rpm}]$ 씩 증가시켜가며
10 회씩 총 110회 전류 데이터를 수집하여 회전속를 추정하 였다. 유도전동기의 정상상태 운전 구간에서 $\mathrm{RSH}$ 속도 추 정 알고리즘을 통해 추정된 회전속도가 실제 회전 속도와 일치하는 것을 확인하였다. 그래프의 우측 축은 실제 회전 속도와 추정 속도 간의 절대 오차율을 나타내는 스케일이 다. 오차율 그래프를 확인해 보면 오차율은 $0.1[\%]$ 이내로 속도 추정의 정확도가 높음을 확인하였다.

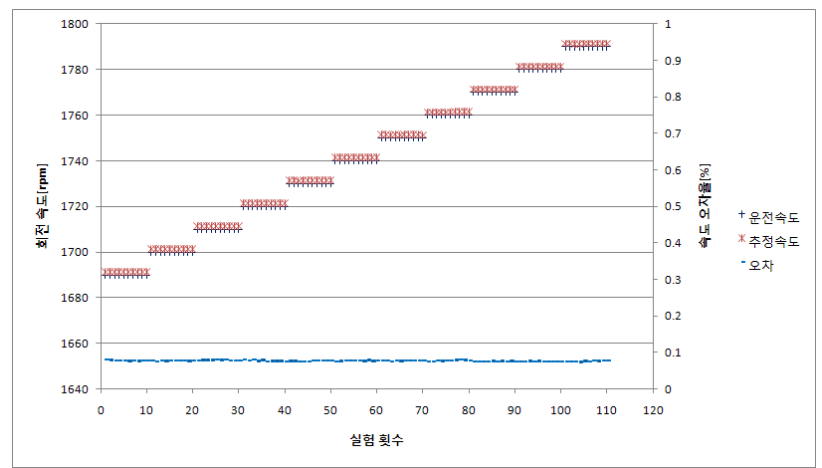

그림 5 유도전동기의 운전 속도와 추정 속도의 비교

Fig. 5 Compare of operation speed and estimation speed of induction motor

\section{3. 결 론}

본 논문에서는 유도전동기의 회전자 바 고장 진단을 위해 정상상태 운전 유도전동기의 회전자 슬롯 하모닉 주파수를 이용하여 속도 센서 없이 정확한 회전속도를 추정하는 방법 을 제안하고, 실용성을 확인하였으며 다음과 같은 결론을 얻 었다.

유도전동기의 회전에 따라 발생하는 두 가지의 회전자 슬 롯 하모닉 주파수 $\left(f_{s h \pm 1}\right)$ 중 $f_{s h 1}$ 가 $f_{s h-1}$ 에 비해 진폭이 더 크게 나타나 $f_{s h 1}$ 주파수를 이용하는 것이 회전속도를 추정 하는데 있어 더 유리함을 확인하였다.

정상 상태 운전 구간에서 회전속도를 변화시켜가며 실험 한 결과 본 논문에서 제안한 회전자 슬롯 하모닉 주파수 검 출 대역에서 가장 큰 진폭을 갖는 주파수가 회전자 슬롯 하 모닉 주파수 $\left(f_{s h 1}\right)$ 임을 확인하였다. 따라서 회전자 슬롯 하모 닉 주파수 검출 대역에서 $f_{s h 1}$ 을 검출하여 회전속도를 추정 할 수 있다.

유도전동기의 정격속도에 따른 회전자 슬롯 하모닉 주파 수 검출 대역을 지정하여 정격 주파수에서 운전되는 유도전 동기의 정상 상태에서의 회전속도는 제안한 추정식으로 추 정이 가능하며, 실제 회전속도와 비교한 결과 오차율 $0.1[\%]$ 이내로 정확한 회전속도 추정이 가능하다.

\section{참 고 문 헌}

[1] Dae-Cheul Shin, Young-Hwan Kim, "A Study of Rotor Fault Detection for the Induction Motor Using Axial Leakage Magnetic Flux," Journal of KIEE, Vol. 20, No. 1, January 2006. 
[2] Toshiyuki Kanmachi and Isao Takahashi, "Sensorless speed control of an induction motor with no influence of secondary resistance variation," IEEE IAS Annual Meetion conference record, pp 408-413, 1993.

[3] 최연옥, 정병호, 조금배, 백형래, 신사현, “확장된 칼만 필터를 이용한 센서없는 유도전동기의 속도추정," 전력 전자학술대회 논문집 . pp.21-24. 1999.

[4] 이정철, 박기태, 정동화, " $\mathrm{FNN}$ 과 $\mathrm{ANN}$ 을 이용한 유도 전동기의 속도 제어 및 추정," 전자공학회 논문지-SC, pp.77 82, 2005.

[5] 김상욱, 나재두, 김영석, "이원관측기를 이용한 유도전 동기의 속도 추정," 전력전자학술대회 논문집. pp.11-19, 1997.

[6] Ichiro Miyashita, Akio Imayanagida and Takashi Koga, "Recent industrial application of speed sensorless vector conrtol in japan," Preceeding IECON'94, pp.1573-1578, 1994.

[7] Hisao Kubota and Kouki Marsure, "Speed sensorless field oriented control of induction motor with rotor resistance adaption," IEEE Trans. Industry Applications, vol30, no.5, pp.1219-1224, 1994.

[8] 정재천, 양보석, 송명현, “전원 신호분석 기술에 의한 회전기기 진단," 인터비젼 pp.241-250, 2008.

[9] R Blasco, M Sumner and G M Asher, "Speed measurement of inverter fed induction motors using the FFT and the rotor slot harmonics", Power Electronics and Variable-Speed Drives, Fifth International Conference on, pp.470-475, Oct 1994.

[10] Kevin D. Hurst, Thomas G. Habetler, " Sensorless speed measurement using current harmonic spectral estimation in induction machine drives," Power Electronics, IEEE Transactions on, pp.66'-73, Jan 1996.

[11] Pillay, P, Xu, Z, "Motor current signature analysis," IAS 96, Conference Record of the IEEE, pp.587-594, 1996.

[12] Pillay, P, Xu, Z, "Labview implementation of speed detection for mains-fed motor using motor current signature analysis," Power Engineering Review, IEEE, pp.47-48, June 1998.

[13] Nandi, S. "Slot permeance effects on rotor slot harmonics in induction machines," IEMDC'03. IEEE International, pp.1633-1639, June 2003.
[14] Qianxiang Li, Jingtao Hu, "A high accuracy FFT algorithm for induction motor sensor-less speed estimation," ICEMS. International Conference on, pp. 851-854, Oct. 2008.

[15] P. L. Alger, Induction Machines-Their Behavior and Uses. New York: Gordon and Breach, 1970.

[16] 양철오, 이경석, 이대성, 박규남, 송명현, “회전자 슬롯 고조파를 이용한 유도전동기의 회전속도 검출,” 대한전 기학회 하계학술대회 논문집, pp.2077-2088, 2011.
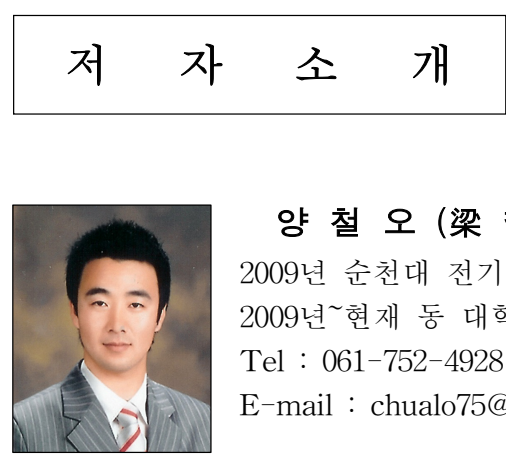

\section{양 철 오 (梁 哲 午)}

2009년 순천대 전기공학과 석사 졸업 2009년 현재 동 대학원 박사과정

Tel : 061-752-4928

E-mail : chualo75@naver.com

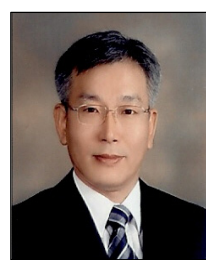

\section{박 규 남 (朴 奎 南)}

전남대 전기공학과 졸업 공박 1984년 현재 순천대 전기제어공학과 교수 Tel : 061-750-3541

E-mail : knpark@sunchon.ac.kr

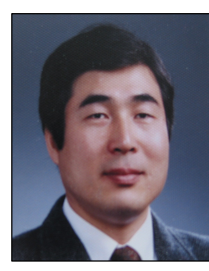

\section{송 명 현 (宋 明 現)}

고려대 전기공학과 졸업 공박

1977년 1981년 삼성전자(주) 모터설계

1988년 현재 순천대 전기제어공학과 교수

Tel : 061-750-3542

E-mail : mhsong@sunchon.ac.kr 